\title{
Unsaturated Keto and Exomethylene Pyranonucleoside Analogues of Thymine and Uracil Exhibit Potent Antioxidant Properties
}

\author{
Chrysoula Spanou ${ }^{1}$, Niki Tzioumaki ${ }^{2}$, Stella Manta $^{2}$, Panagiotis Margaris ${ }^{1,2}$, Dimitrios Kouretas ${ }^{1}$, \\ Dimitri Komiotis $^{2}$, Kalliopi Liadaki ${ }^{*}$

\footnotetext{
${ }^{1}$ Department of Biochemistry and Biotechnology, Laboratory of Animal Physiology, University of Thessaly, Larissa, Greece; ${ }^{2}$ Department of Biochemistry and Biotechnology, Laboratory of Organic Chemistry, University of Thessaly, Larissa, Greece.
} \\ Email:kliad@bio.uth.gr
}

Received March 29 $9^{\text {th }}, 2011$; revised April 30 ${ }^{\text {th }}, 2011$; accepted June $22^{\text {nd }}, 2011$.

\begin{abstract}
Nucleoside analogues play an important role in the development of antitumor and antiviral agents. Specific sugar modified pyranonucleosides, like the keto and exocyclic methylene nucleosides, have been studied for their biological properties, but there is little information regarding their antioxidant activity. The present study reports the antioxidant activity of a series of $\alpha, \beta$-unsaturated 2'- or 4'- keto and exomethylene 5'-hydroxymethyl-lacking pyranonucleosides. The antioxidant activity was evaluated using an in vitro assay which is based on the capacity to protect DNA strand scission induced by peroxyl radicals (ROO'). The majority of the tested nucleoside analogues exhibit potent antioxidant properties against $R^{\circ}{ }^{*}$ radicals. We conclude that the presence of a carbon-carbon double bond at $\alpha, \beta$-disposition to exomethylene group at position 2 of the sugar moiety and the substitution of thymine with uracil improves the antioxidant capacity of these analogues.
\end{abstract}

Keywords: D-Lyxopyranonucleoside Derivatives, D-Arabinonucleoside Derivatives, DNA Damage, Peroxyl Radicals.

\section{Introduction}

Nucleosides are structural modules of nucleic acids with fundamental importance in all living systems [1]. They constitute the basis for development of antitumor and antiviral agents because they act as selective inhibitors of key enzymes involved in cancer or viral replication [2], or as nucleic acid chain terminators which interrupt cellular replication [3-6]. Sugar modified pyranonucleosides are recognized as an important class of biologically active molecules [7-12]. Among them, unsaturated keto [13-15], as well as exomethylene pyranonucleoside analogues [16-19], exhibit interesting antitumor and antiviral properties, while early studies demonstrated that the presence of a primary hydroxyl and hydroxymethyl group in the sugar moiety does not seem to be critical for biological activity [18,20-21].

In order to investigate the antioxidant properties of nucleoside analogues we have previously synthesized a new class of unsaturated 3'-fluoro-4'-ketonucleosides, that of $N^{4}$-benzoyl cytosine and $N^{6}$-benzoyl adenine, respectively [19]. Most of the aforementioned com- pounds showed significant ability to protect DNA from the strand breaking activity of ROO ${ }^{\circ}$ radicals. Furthermore, those nucleoside analogues containing an $\alpha, \beta$-unsaturated keto system were the most potent against the activity of ROO' radicals.

In extending these studies the antioxidant activity of a series of $\alpha, \beta$-unsaturated 2'- or 4'- keto and exomethylene 5'-hydroxymethyl-lacking pyranonucleoside analogues was investigated. Specifically, the present study is the first attempt to correlate structural modifications of the aforementioned nucleoside analogues with the ability to inhibit $\mathrm{ROO}^{\circ}$ radicals-induced DNA damage.

\section{Results}

Five out of the eight tested nucleoside analogues inhibited the DNA damage induced by ROO ${ }^{\circ}$ radicals (Table 1). Compound 4 was the most potent as it exhibited $22 \%$ inhibition of radical-induced DNA damage at the concentration of $20 \mu \mathrm{M}$. It should be noted that all compounds had no effect on plasmid conformation when they were tested alone at the highest concentration. 


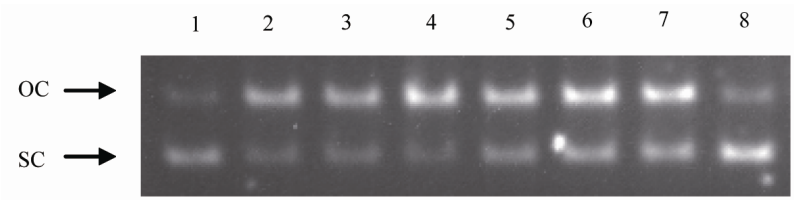

Figure 1. Effect of nucleoside analogue 4 on peroxyl radical-induced plasmid DNA strand scission. Bluescript-SK + plasmid DNA $(1 \mu \mathrm{g} / 10 \mu \mathrm{L})$ was incubated in the presence of 2.5 mM AAPH for $45 \mathrm{~min}$ in the dark and the reaction products were analyzed in $0.8 \%$ agarose gel. Lane 1: negative control. Lane 2: $2.5 \mathrm{mM}$ AAPH. Lanes 3-7: AAPH plus $5,10,20,50,100 \mu \mathrm{M}$ of the nucleoside analogue respectively. Lane 8: plasmid DNA plus $100 \mu \mathrm{M}$ of the nucleoside analogue. OC: open circular; SC: supercoiled.

The presence of an exomethylene group at 2' position compared to the 4' position of the sugar moiety seems to be important for the antioxidant properties of the nucleoside analogues. Specifically, compounds 1 and 3 which contain the exomethylene group at 4' position of the sugar moiety had no activity, while their corresponding compounds 2 and 4 which contain the exomethylene group at 2' position exhibited potent antioxidant activity (Table 1). Compound 2 inhibited $\mathrm{ROO}^{\circ}$ radicals to $16 \%$ and $36 \%$ at 50 and $100 \mu \mathrm{M}$ respectively and compound 4 was a potent inhibitor even at $20 \mu \mathrm{M}$ (Table 1 and Figure 1). The differences in the potency observed between compounds 2 and 4 can be attributed to the different nucleobase (thymine and uracil respectively).

Similar to the exomethylene group the effect of the position of an unsaturated keto system in these nucleoside analogues was examined. Compound 5 had no inhibitory activity at any concentration, while compound $\mathbf{6}$ had antioxidant activity only at the highest tested concentration $(100 \mu \mathrm{M})$. Both compounds have thymine as nucleobase but differ at the position of the unsaturated keto system. It is possible that the translocation of the keto group at position 2' favors the antioxidant activity of the compounds. However, this is not the case when thymine is replaced by uracil, as exhibited by the similar antioxidant capacities of compounds 7 and 8 (22\% and $19 \%$ inhibition at $100 \mu \mathrm{M}$ respectively).

\section{Discussions}

The present study reports the antioxidant properties of $\alpha, \beta$-unsaturated keto and exomethylene D-arabino- and D-lyxo-pyranonucleoside analogues with thymine and uracil as heterocyclic base. Specifically, these nucleoside analogues were evaluated for the ability to inhibit ROO' radicals-induced DNA damage.

Our results demonstrate that the $\alpha, \beta$-unsaturated 2'exomethylene nucleosides exhibit potent antioxidant activities. This property is further reinforced when the nucleobase thymine is replaced by uracil. The potent antioxidant properties of these compounds can be explained by a radical stabilization resonance effect, which can be attributed to their structural properties. It should be mentioned that the $\alpha, \beta$-unsaturated 4'-exomethylene nucleosides had no antioxidant properties.

In contrast to the exomethylene group the influence of the keto group in the antioxidant properties of these compounds is less efficient. The $\alpha, \beta$-unsaturated 2'-keto nucleosides exhibit antioxidant properties only at concentrations of $100 \mu \mathrm{M}$. The 2'-keto and the 4'-keto uracil nucleoside analogues showed similar antioxidant properties which does not apply to the 2'-keto and the 4'-keto thymine analogues. These results point to a nucleobase preference since the substitution of thymine with the smaller uracil leads to compounds with increased antioxidant abilities. It seems that uracil might be beneficial for the interaction of these compounds with the specific radicals.

\section{Conclusions}

The results of this study demonstrate that the presence of a carbon-carbon double bond at $\alpha, \beta$-disposition to exomethylene group at 2'-position of the sugar moiety and uracil as nucleobase improves the antioxidant capacity of the nucleoside analogues. These might be necessary structural modifications that favor the interaction of these nucleosides with the radicals. $\mathrm{ROO}^{\circ}$ radicals are involved as a major initiating factor in lipid peroxidation chain reactions [22]. Thus, the ability of the tested compounds to protect DNA strand breakage by scavenging peroxyl radicals could suggest that these compounds may also prevent lipid peroxidation. Based on the above findings it would be interesting to further investigate the potential effectiveness of these nucleoside analogues in the prevention and probably the treatment of diseases caused by overproduction of free radicals. Further in vitro studies are required to elucidate the exact mechanisms involved in the antioxidant activity of these compounds.

\section{Experimental}

\subsection{General}

2.2'-azo-bis-2-amidinopropane dihydrochloride (AAPH) was purchased from Sigma-Aldrich (St Louis MO, USA). Bluescript-SK + plasmid DNA was isolated from a large scale bacterial culture. All chemicals and solvents used were of the highest quality commercially available.

\subsection{Nucleoside analogues}

Nucleoside analogues 1, 3, 5 and 7 were previously syn- 
Table 1. Antioxidant properties of nucleosides analogues against ROO' radical induced DNA damage.

\begin{tabular}{|c|c|c|c|c|c|c|}
\hline & \multirow{2}{*}{ Compounds } & \multicolumn{5}{|c|}{ \% Inhibition } \\
\hline & & $5 \mu \mathrm{M}$ & $10 \mu \mathrm{M}$ & $20 \mu \mathrm{M}$ & $50 \mu \mathrm{M}$ & $100 \mu \mathrm{M}$ \\
\hline 1 & & $\mathrm{NI}^{\ddagger}$ & NI & NI & NI & NI \\
\hline 2 & & NI & NI & NI & $16 \pm 1^{\dagger^{*}}$ & $36 \pm 3^{*}$ \\
\hline 3 & & NI & NI & NI & NI & NI \\
\hline 4 & & NI & NI & $22 \pm 1^{*}$ & $21 \pm 3^{*}$ & $25 \pm 2^{*}$ \\
\hline 5 & & NI & NI & NI & NI & NI \\
\hline 6 & & NI & NI & NI & NI & $9 \pm 1^{*}$ \\
\hline 7 & & NI & NI & $\mathrm{NI}$ & NI & $22 \pm 3^{*}$ \\
\hline 8 & & NI & NI & NI & NI & $19 \pm 2^{*}$ \\
\hline
\end{tabular}

${ }^{\star} \mathrm{NI}$ : no significant inhibition. ${ }^{\dagger}$ Values are the means $\pm \mathrm{SE}$ of the percent inhibition from three independent experiments. ${ }^{*} \mathrm{p}<0.05$ when compared with control (plasmid DNA plus AAPH). Thy: Thymine, U: Uracil. 
thesized [18] and analogues 2, 4, 6 and 8 were also previously synthesized [23]. All analogues were freshly prepared in DMSO.

\subsection{Peroxyl Radical-Induced DNA Strand Scission Assay}

The assay was performed using the method described by Chang et al. [24]. Peroxyl radicals were generated from thermal decomposition of AAPH. The reaction mixture $(10 \mu \mathrm{L})$ containing $1 \mu \mathrm{g}$ Bluescript-SK + plasmid DNA, $2.5 \mathrm{mM}$ AAPH in phosphate-buffered saline (PBS: 137 $\mathrm{mM} \mathrm{NaCl}, 2.7 \mathrm{mM} \mathrm{KCl}, 8.1 \mathrm{mM} \mathrm{Na}_{2} \mathrm{HPO}_{4}, 1.5 \mathrm{mM}$ $\mathrm{KH}_{2} \mathrm{PO}_{4}$ ) and the tested product at different concentrations $(5,10,20,50,100 \mu \mathrm{M})$ was incubated in darkness for $45 \mathrm{~min}$ at $37^{\circ} \mathrm{C}$. AAPH was added last right before incubation. The reaction was terminated by the addition of $3 \mu \mathrm{L}$ loading buffer $(0.25 \%$ bromophenol blue and $30 \%$ glycerol) and analyzed in $0.8 \%$ agarose gel electrophoresis at $70 \mathrm{~V}$ for $1 \mathrm{~h}$. The gels were stained with ethidium bromide $(0.5 \mu \mathrm{g} / \mathrm{mL})$, destained with water, photographed by UV translumination using the Vilber Lourmat photodocumentation system (DP-001.FDC) (Torcy, France) and analyzed with Gel-Pro Analyzer version 3.0 (MediaCybernetics, Silver Spring, USA). Each experiment was carried out in triplicate. The use of DMSO at the tested concentrations did not affect the results of the assay.

\subsection{Inhibition of Free Radical-Induced DNA Damage}

The induction of DNA strand breaks by peroxyl (ROO') was measured by the conversion of supercoiled Bluescript-SK + plasmid double stranded DNA to the open circular conformation analyzed in agarose gel electrophoresis. Preventive activity of the tested samples was assessed by the inhibition of conversion of supercoiled (unnicked) conformation to open circular (nicked). The percentage inhibition of radical-induced DNA strand cleavage by the tested compounds was calculated using the following equation:

$$
\% \text { inhibition }=\frac{S_{p}-S}{S_{p}-S_{o}} \times 100
$$

where $S_{0}$ is the percentage of supercoiled conforma- tion in the negative control sample (plasmid DNA alone), $S_{p}$ is the percentage of supercoiled conformation in the positive control sample (plasmid DNA with the radical initiating factor) and $S$ is the percentage of supercoiled conformation in the sample containing plasmid DNA, the tested compound and the radical initiating factor. It should be noted that prior to treatment Bluescript-SK + plasmid DNA contained approximately $10 \%-20 \%$ open circular DNA.

\subsection{Statistical Analysis}

All results are expressed as mean $\pm \mathrm{SD}(\mathrm{n}=3)$. Statistical computations were carried out using the SPSS 13.0 software. For statistical analysis, one-way ANOVA was applied followed by Dunnett's test for multiple pair-wise comparisons. Dose response relationships were examined by Spearman's correlation analysis. Differences were considered significant at $\mathrm{p}<0.05$.

\section{Acknowledgements}

This work has been funded by the Postgraduate Programs of "Biotechnology-Quality Assessment in Nutrition and the Environment" and "Molecular Biology and Genetics Applications-Diagnostic Markers" of the Department of Biochemistry and Biotechnology of the University of Thessaly.

\section{References}

[1] G. Gumina, Y. Chong, H. Choo, G. Song and C. K Chu, "L-Nucleosides: Antiviral Activity and Molecular Mechanicsm," Current Topics in Medicinal Chemistry, Vol. 2, No. 10, 2002, pp. 1065-1086. doi:10.2174/1568026023393138

[2] D. C. Orr, H. T. Figueiredo, C. L. Mo, C. R. Penn and J. M. Cameron, "DNA Chain Termination Activity and Inhibition of Human Immunodeficiency Virus Reverse Transcriptase by Carbocyclic 2',3'-Didehydro-2',3'-Dideoxy-Guanosine Triphosphate," Journal of Biological Chemistry, Vol. 267, No. 6, 1992, pp. 4177-4182.

[3] M. A. Turner, X. Yang, D. Yin, K. Kuczera, R. T. Borchardt and P. L. Howell, "Structure and Function of SAdenosylhomocysteine Hydrolase," Cell Biochemistry and Biophysics, Vol. 33, No. 2, 2000, pp. 101-125. doi:10.1385/CBB:33:2:101

[4] Y. Kitade, A. Kozaki, T. Miwa and M. Nakanishi, "Synthesis of Base-Modified Noraristeromycin Derivatives and Their Inhibitory Activity against Human and Plasmodium Falciparum Recombinant S-Adenosyl-L-Homocysteine Hydrolase," Tetrahedron, Vol. 58, No. 7, 2002, pp. 1271-1277.

[5] K. S. Anderson, "Perspectives on the Molecular Mechanicsm of Inhibition and Toxicity of Nucleoside Analogs That Target HIV-1 Reverse Transcriptase," Biochimica et Biophysica Acta, Vol. 1587, No. 2-3, 2002, pp. 296-299.

[6] G. Maga and S. Spadari, "Combinations against Combinations: Associations of Anti-HIV 1 Reverse Transcriptase Drugs Challenged by Constellations of Drug Resistance Mutations," Current Drug Metabolism, Vol. 3, No. 1, 2002, pp. 73-96. doi:10.2174/1389200023337982

[7] M. J. Egron, F. Leclercq, K. Antonakis, I. Bennani-Baiti and C. Frayssinet, "Synthesis and Antineoplastic Properties of 3'-Deoxy-3'-Fluoroketonucleoside Derivatives. Correlations between Structure and Biological Activity," 
Carbohydrate Research, Vol. 248, 1993, pp. 143-150. doi:10.1016/0008-6215(93)84122-M

[8] M. Alaoui, M. J. Egron, M. Bessodes, K. Antonakis and I. Chouroulinkov, "Relationship between the Structure and Cytotoxic Activity of New Unsaturated Ketonucleosides Tested on Eight Cell Lines," European Journal of Medicinal Chemistry, Vol. 22, No. 4, 1987, pp. 305-310. doi:10.1016/0223-5234(87)90267-4

[9] F. Leclercq and K. Antonakis, "Unsaturated Ketonucleotides: Synthesis of $\alpha$ and $\beta$ Anomers of 1-(2,3-dideoxy-6-O-diethoxyphosphoryl-D-glycero-hex-2-enopyranosyl-4-ulose) Thymine," Carbohydrate Research, Vol. 263, No. 2, 1994, pp. 309-313. doi:10.1016/0008-6215(94)00168-5

[10] G. S. Bisacchi, S. T. Chao, C. Bachard, J. P. Daris, S. Innaimo, G. A. Jacobs, O. Kocy, P. Lapointe, A. Martel, Z. Merchant, W. A. Slusarchyk, J. E. Sundeen, M. G. Young, R. Colonno and R. Zahler, "BMS-200475, a Novel Carbocyclic 2'-Deoxyguanosine Analog with Potent and Selective Anti-Hepatitis B Virus Activity in $\mathrm{Vi}$ tro," Bioorganic \& Medicinal Chemistry Letters, Vol. 7, No. 2, 1997, pp. 127-132. doi:10.1016/S0960-894X(96)00594-X

[11] S. J. Yoo, H. O. Kim, Y. Lim, J. Kim and L. S. Jeong, "Synthesis of Novel (2R,4R)- and (2S,4S)-Iso-Dideoxynucleosides with Exocyclic Methylene as Potential Antiviral Agents," Bioorganic \& Medicinal Chemistry, Vol. 10 , No. 1,2002 , pp. $215-226$ doi:10.1016/S0968-0896(01)00266-8

[12] P. Gunaga, M. Baba and L. S. Jeong, "Asymmetric Synthesis of Novel Thioisodideoxynucleosides with Exocyclic Methylene as Potential Antiviral Agents," Journal of Organic Chemistry, Vol. 69, No. 9, 2004, pp. 3208-3211.

[13] S. Manta, G. Agelis, T. Botić, A. Cencič and D. Komiotis, "Fluoro-Ketopyranosyl Nucleosides: Synthesis and Biological Evaluation of 3-fluoro-2-keto- $\beta$-D-glucopyranosyl Derivatives of N4-benzoyl Cytosine," Bioorganic \& Medicinal Chemistry, Vol. 15, No. 2, 2007, pp. 980-987. doi:10.1016/j.bmc.2006.10.033

[14] S. Manta, G. Agelis, T. Botić, A. Cencič and D. Komiotis, "Unsaturated Fluoro-Ketopyranosyl Nucleosides: Synthesis and Biological Evaluation of 3-fluoro-4-keto- $\beta$-Dglucopyranosyl Derivatives of N4-benzoyl Cytosine and N6-benzoyl Adenine," European Journal of Medicinal Chemistry, Vol. 43, No. 2, 2008, pp. 420-428. doi:10.1016/j.ejmech.2007.04.001

[15] S. Manta, E. Tsoukala, N. Tzioumaki, A. Goropevšek, R. T. Pamulapati, A. Cencič, J. Balzarini and D. Komiotis, "Dideoxy Fluoro-Ketopyranosyl Nucleosides as Potent Antiviral Agents: Synthesis and Biological Evaluation of 2,3- and 3,4-dideoxy-3-fluoro-4- and -2-keto- $\beta$-D-glucopyranosyl Derivatives of N4-benzoyl Cytosine," European Journal of Medicinal Chemistry, Vol. 44, No. 6, 2009, pp. 2696-2704. doi:10.1016/j.ejmech.2009.01.020

[16] G. Agelis, N. Tzioumaki, T. Botić, A. Cencič and D. Komiotis, "Exomethylene Pyranonucleosides: Efficient
Synthesis and Biological Evaluation of 1-(2,3,4-trideoxy2-methylene- $\beta$-D-glycero-hex-3-enopyranosyl)thymine," Bioorganic and Medicinal Chemistry, Vol. 15, No. 16, 2007, pp. 5448-5456. doi:10.1016/j.bmc.2007.05.055

[17] G. Agelis, N. Tzioumaki, T. Tselios, T. Botić, A. Cencič and D. Komiotis, "Synthesis and Molecular Modelling of Unsaturated Exomethylene Pyranonucleoside Analogues with Antitumor and Antiviral Activities," European Journal of Medicinal Chemistry, Vol. 43, No. 7, 2008, pp. 1366-1375. doi:10.1016/j.ejmech.2007.10.014

[18] N. Tzioumaki, E. Tsoukala, S. Manta, G. Agelis, J. Balzarini and D. Komiotis, "Synthesis, Antiviral and $\mathrm{Cy}$ tostatic Evaluation of Unsaturated Exomethylene and keto D-lyxopyranonucleoside Analogues," Archiv der Pharmazie, Vol. 342, No. 6, 2009, pp. 353-360. doi:10.1002/ardp.200900004

[19] C. Spanou, S. Manta, D. Komiotis, A. Dervishi and D. Kouretas, "Antioxidant Activity of a Series of Fluorinated Pyrano-nucleoside Analogues of N4-benzoyl Cytosine and N6-benzoyl Adenine," International Journal of Molecular Sciences, Vol. 8, No. 7, 2007, pp. 695-704. doi: $10.3390 / 18070695$

[20] S. Manta, N. Tzioumaki, E. Tsoukala, A. Panagiotopoulou, M. Pelecanou, J. Balzarini and D. Komiotis, "Unsaturated Dideoxy Fluoro-Ketopyranosyl Nucleosides as New Cytostatic Agents: A Convenient Synthesis of 2,6dideoxy-3-fluoro-4-keto- $\beta$-D-glucopyranosyl Analogues of Uracil, 5-Fluorouracil, Thymine, N4-benzoyl Cytosine and N6-benzoyl Adenine," European Journal of Medicinal Chemistry, Vol. 44, No. 11, 2009, pp. 4764-4771. doi:10.1016/j.ejmech.2009.06.013

[21] S. Manta, E. Tsoukala, N. Tzioumaki, C. Kiritsis, J. Balzarini and D. Komiotis, "Synthesis of 4,6-dideoxy-3fluoro-2-keto- $\beta$-D-glucopyranosyl Analogues of 5-Fluorouracil, N6-Benzoyl Adenine, Uracil, Thymine, N4-Benzoyl Cytosine and Evaluation of Their Antitumor Activities," Bioorganic Chemistry, Vol. 38, No. 2, 2010, pp. 4855. doi:10.1016/j.bioorg.2009.11.001

[22] C. Mylonas and D. Kouretas, "Lipid Peroxidation and Tissue Damage," In Vivo, Vol. 13, No. 3, 1999, pp. 295310. doi:10.1016/j.ejmech.2011.01.005

[23] N. Tzioumaki, S. Manta, E. Tsoukala, J. V. Voorde, S. Liekens, D. Komiotis and J. Balzarini, "Synthesis and Biological Evaluation of Unsaturated Keto and Exomethylene D-Arabinopyranonucleoside Analogues: Novel 5-Fluorouracil Analogues That Target Thymidylate Synthase," European Journal of Medicinal Chemistry, Vol. 46, No. 4, 2011, pp. 993-1005. doi:10.1021/jf0100907

[24] S. T. Chang, J. H. Wu, S. Y. Wang, P. L. Kang, N. S. Yang and L. F. Shyur, "Antioxidant Activity of Extracts from Acacia Confusa Bark and Heartwood," Journal of Agricultural and Food Chemistry, Vol. 49, No. 7, 2001, pp. 3420-3424. 